\title{
Diagnosis ofacute cholecystitis using ultrasonography
}

\author{
Moawia Gameraddin ${ }^{1,}$ Suliman Salih ${ }^{12},{ }^{1}$,Abdulrahim Suliman ${ }^{3},{ }^{, 6}$ \\ Mohamed yousef ${ }^{4,5}$ \\ ${ }^{I}$ Department of Diagnostic Radiologic Technology, College of Medical Applied Sciences, Taibah University \\ Fax:00966 8475790 P.O: 30001 AlmadinahAlmunawwarah, KSA \\ ${ }^{2}$ Faculty of Radiological Sciences and Medical Imaging, AlzaeimAlazhari University.P.O.Box1432 Khartoum \\ Bahri 13311-Sudan \\ ${ }^{3}$ Abulrahim Suliman, kassalHospital, Kassala Town, Sudan \\ ${ }^{4}$ College of Medical Radiologic Science, Sudan University of Science and Technology.P.O.Box 1908, Khartoum, \\ Sudan \\ ${ }^{5}$ Radiologic Technology Department, College of Applied Medical Science , Qassim university, Buraduh \\ KSA . \\ ${ }^{6}$ National Cancer Institute, Gezira University, Sudan.
}

\begin{abstract}
The aim of this study was to analyse the performance of ultrasonography in the diagnosis of acute cholecystitis. We performed an observational retrospective study which included 100 patient with clinical suspected of AC were randomized into two groups. The first group included these patients with final diagnosis of acute cholecystitis and other group included patients with final alternative diagnosis to acute cholecystitis. Study found that the incidence of AC is high in obese, AC incidence is higher within the age of 41-50 years, female (57\%) more affected, Khartoum population suffer more than Omdurman and Kassala (71\%), also tenderness is observed on examination with $38 \%$ and is not exist with $61 \%$. it concluded that ultrasound had a great value in increasing accuracy in diagnosis of acute cholecystitis and it decreases the false negative diagnostic rate and improves the clinical outcome.
\end{abstract}

Key words:Cholecystitis, acute - Gallbladder - Ultrasound, gallbladder. acutecalculouscholecystitis ultrasound diagnosis

\section{Introduction:}

Acute cholecystitis (AC) occur as a result of inflammation of the gallbladder was usually secondary to cystic duct obstruction. AC occurs more commonly in children and adults who are critically ill in the form of severe trauma and burns or major surgery, anatomy of gallbladder and extra hepatic biliary systemis essential to all sonologists and surgeon ${ }^{[1]}$. Developmental anatomy is essential because gallbladder and biliary anomalies are not uncommon and the failure to recognize such a congenital problem can result in significant per-operative morbidity ${ }^{[2]}$. In U/S the gall-bladder is a pear shaped anechoic structure, smooth wall in the inferior aspect of the right lobe of the liver ${ }^{[3]}$, anomalies ofthe gallbladder are generally of minimal clinical significance ${ }^{[4]}$. Gallbladder and the duct draining the gallbladder take the course of normal common bile duct to the duodenum ${ }^{[5]}$. All the hepatic cells continually for a small amount of secretion called bile ${ }^{[6]}$. The presence of bile salt and proteins is responsible for the observation of gallbladder bile is isotonic to plasma ${ }^{[7]}$, gallstones are the commonest biliary pathology ${ }^{[8]}$.Modern ultrasound (US) examination of the gall bladder is an effective tool in the diagnosis of acute cholecystitis (AC), especially when used on patients admitted for emergency surgery ${ }^{[9-12]}$. Cholescintigraphy (CS) and US are the first diagnostic imaging modalities that should be used ${ }^{[13,14]}$. Only when ultrasound and scintigraphic signs are unsatisfactory or equivocal ${ }^{[15]}$, would it be necessary to perform computed tomography (CT). With the new real-time scanners, US examination of the gallbladder has become an area of great clinical development. Real-time scanners permit quick and easy visualization of the gallbladder in the majority of patients. Calculi approximately $1 \mathrm{~m} \mathrm{~m}$ in diameter can be imaged under ideal circumstances ${ }^{[16]}$. Acute cholecystitis usually results from obstruction of the gallbladder neck, with subsequentinfection. The gallbladder therefore appears abnormally distended and spherical in shape and the gallbladder wall is edematous and thickened ${ }^{[17]}$. All these features, including the obstructing calculus, can be imaged by US and may be extremely valuable in correctly establishing the diagnosis. The aim of this study was to analyze the performance of ultrasonography in the diagnosis of acute cholecystitis 


\section{Materials and methods:}

Ultrasonic confirmatory studies were performed in different hospitals and clinics in Kassala State from Oct 2008 to Oct 2009 on 100 patients who were clinically suspected of having AC (upper abdominal pain, fever, and leukocytosis). Of these patients, 69 were men and 31 were women, aged between 31 and 89 years (mean, 69).

With ultrasonic signs (gallbladder distention, thickening of gall bladder wall, cholelithiasis, sonolucent halo in the gallbladder wall,fluidsonolucent band surrounding the gallbladder, intraluminal echogenic mass. The ultrasonic examinations were performed on linear electronic real-time equipment with a transducer frequency of 3.5 MHz. Cross-sections were made transversely, longitudinally, and obliquely, with the patient lying on his or her left side.

The data had been collected with clinical data sheet and ultrasound images.

\section{Result}

The study group included 100 patients with a mean ageof \pm years. The descriptive analysis of patientdistribution in age and gender an increased incidence of cholecystitis in female $(57 \%)$ patients, regardless of age group, the most affected group ranged between (41-50) years. For the group of patients diagnosed ultrasonographically

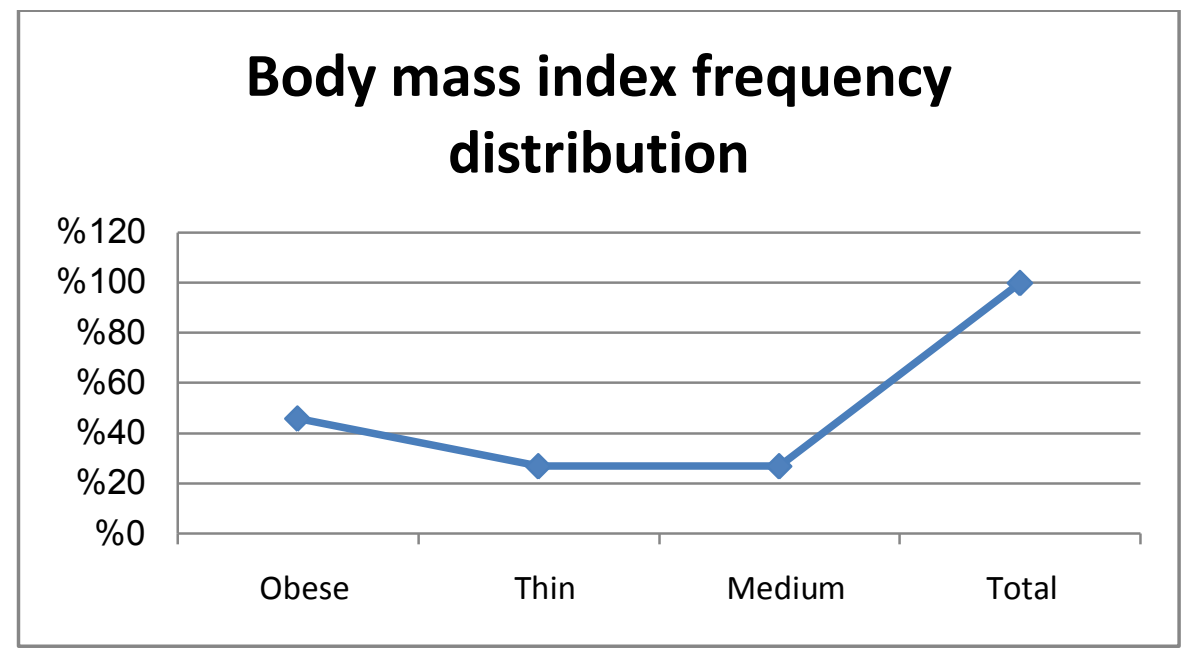

Figure 1.Body mass index frequency distribution

For the group of patients diagnosed ultrasonographically with acute cholecystitis In order to correlate the clinical aspects we analyzed the symptoms and objective signs as recorded. The ultrasonographic examination performed in setting offers information on the parietal alterations. We assessed ultrasonographically in themobility of the calculi in the gallbladder $10.0 \%$ calculiwere mobile and $16.6 \%$ were fixed, Another parameter submitted to analysis was the concordance between of number of gallbladder stone and body mass index, $\mathrm{We}$ found a good correlation between the sizes measured and mass index 


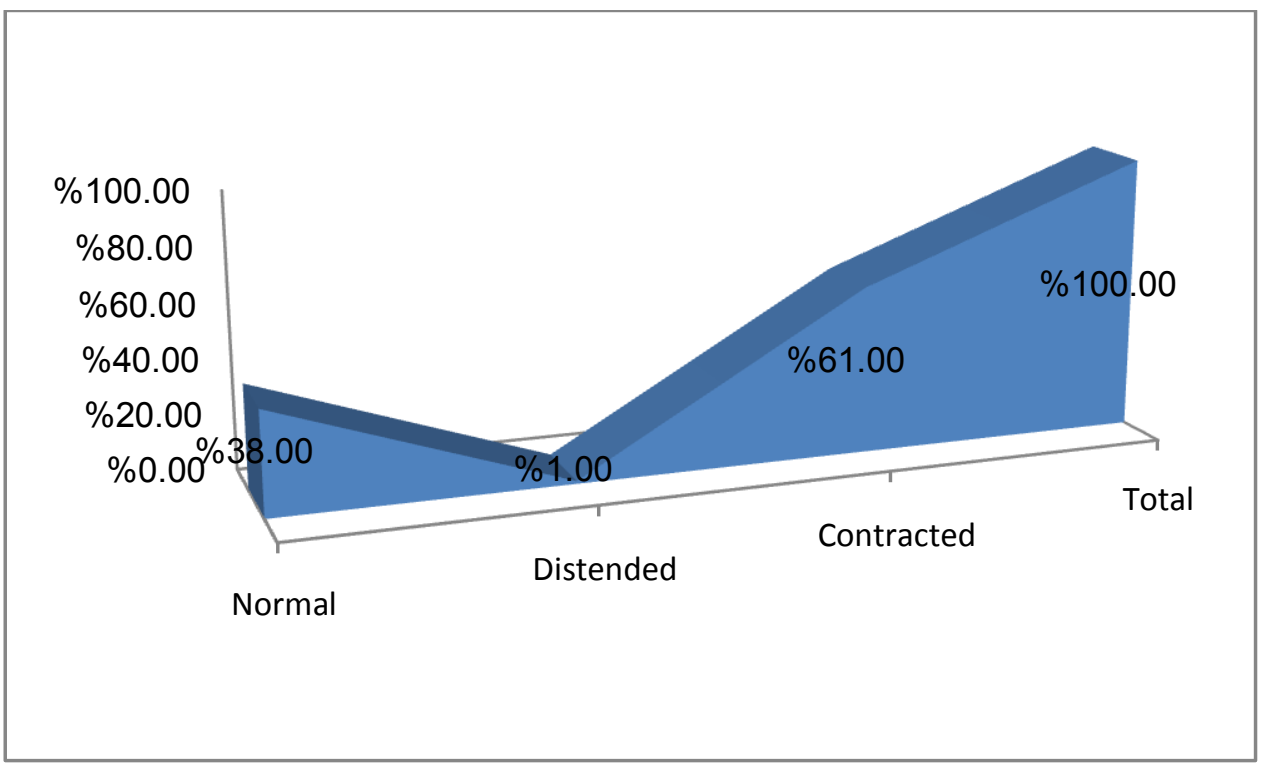

Figure e 2. G.B shape frequency distribution:

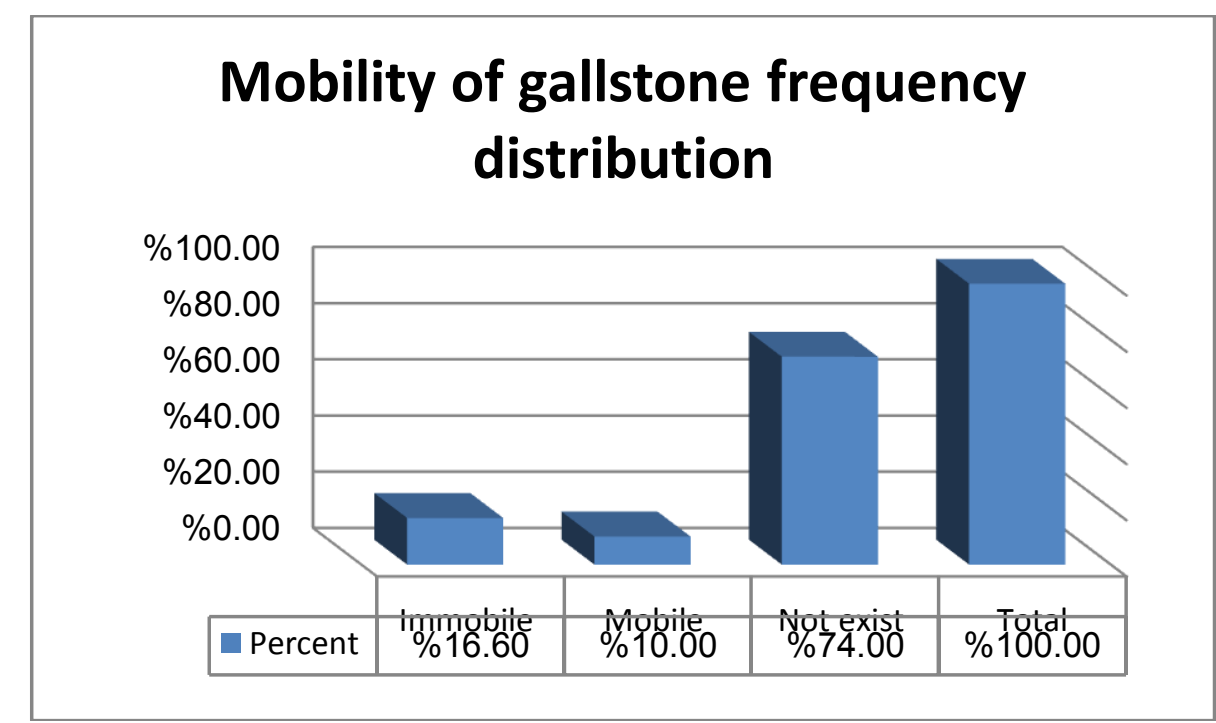

Figure 3. Analysis of mobile versus immobile incidence of gallstones in the gallbladder in US examination

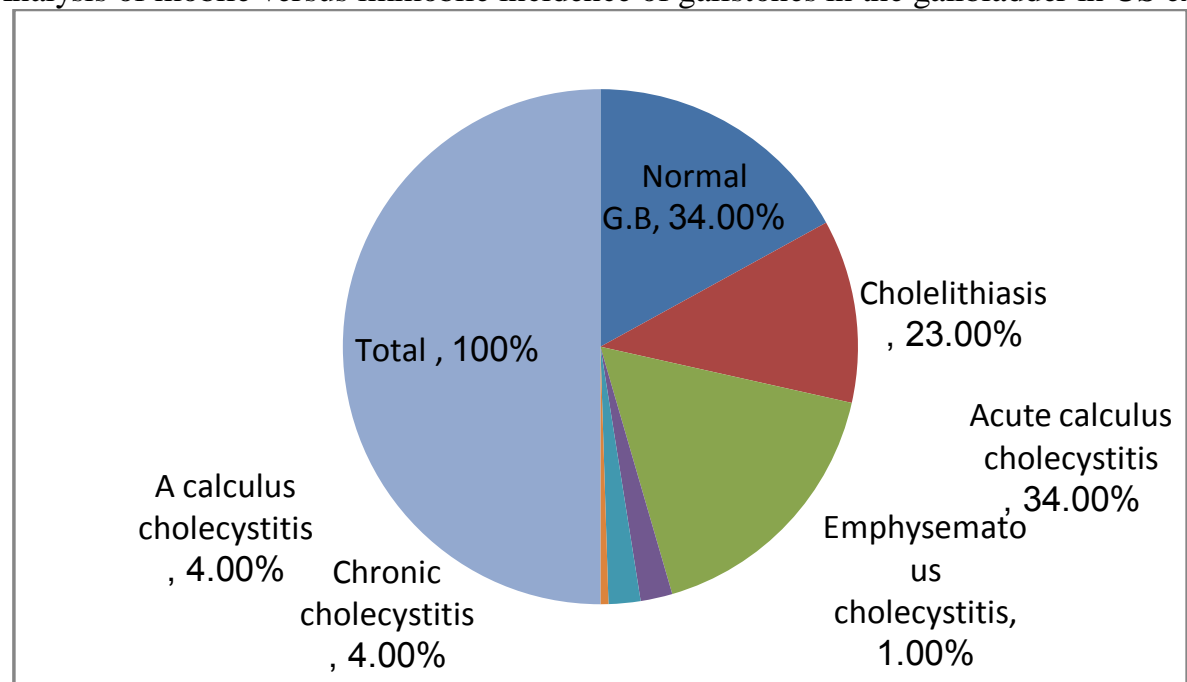

Figure 4.Shows variable distribution of the final diagnosis, it revealed that most of the patient complain of ACC. 


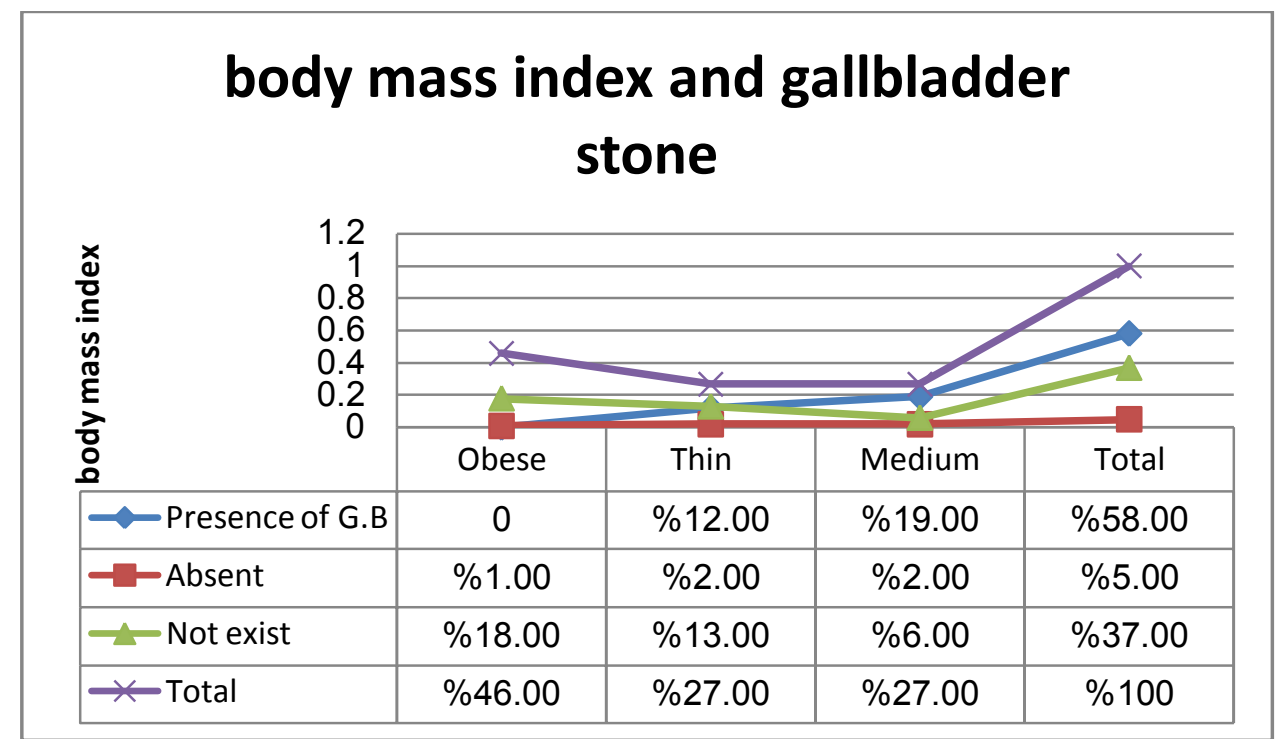

Figure 5. Body mass index and gallbladder stone

Table 1. Frequency distribution of final diagnosis:

\begin{tabular}{|c|c|c|c|c|}
\hline & \multicolumn{3}{|c|}{ GB stone } & \\
\hline Final diagnosis & Presence & Absent & Not & Total \\
\hline Normal G.B & $2.0 \%$ & $2.0 \%$ & $30.0 \%$ & $34 \%$ \\
\hline cholecystitis & $23.0 \%$ & $0 \%$ & $0 \%$ & $23.0 \%$ \\
\hline Acute cholecystitis & $0 \% \%$ & $2.0 \%$ & $2.0 \%$ & $4.0 \%$ \\
\hline $\begin{array}{l}\text { chronic } \\
\text { Cholecystitis }\end{array}$ & $4.0 \%$ & $0.0 \%$ & $0.0 \%$ & $4.0 \%$ \\
\hline $\begin{array}{l}\text { Emphysematous } \\
\text { cholecystitis }\end{array}$ & $1.0 \%$ & $0.0 \%$ & $0.0 \%$ & $1.0 \%$ \\
\hline
\end{tabular}

Table 2.bladder wall thickness assessed by ultrasonography

\begin{tabular}{|l|l|l|l|l|}
\hline & Minimum & Maximum & Mean & Std deviation \\
\hline Wall thickness & 2.3 & 8.0 & 3.808 & 1.5345 \\
\hline
\end{tabular}

Table (3): The relationship between age and GB stones age:

\begin{tabular}{|l|l|l|l|l|}
\hline & \multicolumn{2}{|c|}{ GB stones } & \\
\hline Age group & Presence & Absent & Not exist & Total \\
\hline $10-20$ & $2.0 \%$ & $0.0 \%$ & $4.0 \%$ & $6.0 \%$ \\
\hline $21-30$ & $2.0 \%$ & $0 \%$ & $7.0 \%$ & $9.0 \%$ \\
\hline $31-40$ & $9.0 \%$ & $2.0 \%$ & $9.0 \%$ & $20.0 \%$ \\
\hline $41-50$ & $28.0 \%$ & $1.0 \%$ & $10.0 \%$ & $39.0 \%$ \\
\hline $51-60$ & $14.0 \%$ & $1.0 \%$ & $6.0 \%$ & $21.0 \%$ \\
\hline $61-70$ & $2.0 \%$ & $1.0 \%$ & $1.0 \%$ & $4.0 \%$ \\
\hline$>70$ & $1.0 \%$ & $0.0 \%$ & $0.0 \%$ & $1.0 \%$ \\
\hline
\end{tabular}

Table (4): Frequency distribution of wall thickness:

\begin{tabular}{|l|l|l|l|l|}
\hline Groups & Mean & Std deviation & Minimum & Maximum \\
\hline Presence of G.B stones & 4.22 & 1.65 & 2.4 & 8.0 \\
\hline Absent & 3.62 & 1.37 & 2.6 & 6.0 \\
\hline Not exist & 3.18 & 1.14 & 2.3 & 7.0 \\
\hline
\end{tabular}

\section{Discussion}

Acute cholecystitis is the most frequent complication of biliary lithiasis, with the incidence increasing with age, as demonstrated after analyzing thenumber of admissions and cholecystectomies in patients overthe age of $60^{[18,19]}$. US is one of the methods most frequently used in thediagnosis of acute cholecystitis; however, several studies have stressed the limitations of the method related to the operator's expertise, the ultrasound machines used and the possibility of performing the investigation at the bedside ${ }^{[19-21]}$. There are also studies proving the accuracy and advantages of US performed in emergency as compared to hepato- 
biliaryscintigraphy ${ }^{[22,23]}$ or computer tomography ${ }^{[24]}$.Summers and Colab. studied a better accuracy of US performed in the emergency setting than that of the same method performed by radiologists for the identification of surgical conditions such as acute cholecystitis ${ }^{[25]}$. The originality of the study resides in the correlation of the clinical and ultrasonographic aspects with intra-operatory findings, as well as in the analysis of sonographicrole in the diagnosis of different forms of cholecystitis. The incidence of acute cholecystitis was higher in female patients, andmost of the patient who complain of acute calculuscholecystitis created at age between (41-50) years old, The results of the present study confirm the variations in lithiasis incidence, as stated in the epidemiological literature ${ }^{[26,27]}$. We also found an increased incidence of the disease in patients from an urban areas, revealed that most of Khartoum population complain a lot from (ACC) ,represent71\% ,comparewith Kassala and Omdurman. But the difference decreased in the over 60 age grou,represent $5.0 \%$.It was observed thatacute calculuscholecystitiswere common in obese patients (46\%).There is, however, an important proportion of patients presenting with tenderness when putting the probe on the right upper quadrant area $(38 \%)$.Jaundicerepresents $21 \%$ of patients whocame with high leucocytosisand $79 \%$ were not with high leucocytosis. There is strong relation between body mass index and gallbladder stone, gallstone $19 \%$ percentage as increase when compare with thin and medium patient, this due to increase consumption of fatty ducts which elevate the cholesterollevels..Strong relation between the body mass index and gallstones, there is $53 \%$ of the patient who came for abdomen ultrasound and the other $47 \%$ percentage is for thin and medium patients. It was documented that the sonographic features most frequently encountered in patients with acute cholecystitiswas parietal thickening, also described in literature as correlating with the inflammatory process ${ }^{(28,29)}$. Thestatistical analysis of the mean gallbladder wall thickness $(2.3$ to $8.0 \mathrm{~mm})$, The results of our study confirm the literature data showing statistically significant correlations between the parietal dimensions described ultrasonographically and those measured during surgery byBingener et al ${ }^{[28]}$. Chen and Colab.reported an increasein the conversion risk at a sonographically-measured parietal thickness of more than $6 \mathrm{~mm}^{[30,31]}$. The literature data describe gallstones lodged in the infundibulum as a favoring factor of inflammation ${ }^{[32]}$. The correlation between the ultrasonographicaspect of immobile calculus with the severity of cholecystitis, The result was an increased incidence of acute inflammatory processes in cases with mobile gallstones. The risk analysis confirms the role of emergency US in the assessment of patients with clinical suspicion for acute cholecystitis, especially in patients without previous history of lithiasis. The increased risk the latter have in developing severe forms of acute cholecystitis stresses the contribution of US in optimising surgical therapy, in accordance with actual protocoles for the acute approach of lithiasis complications such as cholecystitis ${ }^{[33,34]}$.In our study, we analyzed the contribution of US in the diagnosis of biliary lithiasis during acute cholecystitis forms $(27.33 \%)$.

\section{Conclusions}

The incidence of acute cholecystitis in the studied group was higher in patients from urban areas, The symptoms and signs found during emergency examination were not specific for the severity of any of the particular type of acute cholecystitis. The statistical analysis of the mean parietal thickness as assessed ultrasonographically in each pathologic type of acute cholecystitis and allowed to discriminate the severity of inflammation in cholecystitis. US is a method of high accuracy for the diagnosis of biliary lithiasis its complication, acute cholecystitis $(87.35 \%)$. The ultrasonographic assessment of gallstone size had a concordance with the sizes measured during surgery. The risk analysis for lithiasis complications and the high risk for patients without previous lithiasis history to develop severe forms of acute cholecystitis stresses the essential contribution of US in optimizing surgical therapy.US can be used as a first intention examination in the Emergency Department for the triage of patients with complicated biliary lithiasis requiring surgical therapy.

[1]. Healey E. Hodge J. Surgical Anatomy, $1^{\text {st }}$ ed. Dresking 1990

[2]. Hunter J.G. Advanced laparoscopic surgery, Anatomy, Physiology-American Journal of Surgery 173: 14-18, 2 ${ }^{\text {nd }}$ ed (1997).

[3]. Bissset R.A, .Khan AN: differential diagnosis in abdominal ultrasound. London: WB Sannders Co, 2002: 159-180.

[4]. Gonzalez AC, Johnson JA. 3ed ed. Ultrasound examination of the gallbladder, a review clin. Radiol. 1978 Mar, 29 (2): 171 -167.

[5]. Tait N-Little JM. BMJ 311: 99-105 (1995)

[6]. Jonesal et al, The architecture of bile secretion Dig Dis Sci. 1980, 25: 609

[7]. Klaassen CD, Watkins JB III: Mechanism of Bile formation Hepatic uptake and Bilary excretion pharmacol Rev $1984,3$.

[8]. Pheils MT, Anderson PT, Silverton RP, Dutaiappah B. acute cholecystitis: the question of early of late operation Aust NZJ Surg. 1973 Jul, 43 (1): 24.

[9]. Bergman AB, Neiman HL, Krant B: Ultrasonographic evaluation of pericholecystic abscesses. A JR 132:201-203,1979

[10]. Kane RA: Ultrasonographic diagnosis of gangrenous cholecystitis and empyema of the gallbladder. Radiology 134: 191-194, 1980

[11]. Martinez A, Caceres J, Perez C : Postoperative acute cholecystitis: sonographic diagnosis. Eur J Radiol 5: 35-37, 1985

[12]. Martinez A, Rosell R: Ultrasonographic criteria in the diagnosis of acute cholecystitis. Radiologla 25:125-130, 1983

[13]. Laing FC, Federle MP, Jeffrey EB, Brown TW: Ultrasonic evaluation of patients with acute right upper quadrant pain. Radiology $140: 449-455,1981$ 
[14]. Whorthen N J, Uszler JM, Funamura JL: Cholecystitis: prospective evaluation of sonography and 99m Tc-HIDA cholescintigraphy. A JR 137: 973-978, 1981

[15]. Kane RA, Costello PH, Diszlak E: Computed tomographyin acute cholecystitis : new observations. A JR 141: 697-701, 1983

[16]. 16-Hessle PC, Hill DS, Deforte FM, Rocco AF: High accuracy sonographic recognition of gallstones. A JR 136:517-520, 1981

[17]. Croce F, Mantali G, Solbiati L, Marinoni G: Sonography in acute cholecystitis. Br J Radio154: 927-931, 1981

[18]. Bateson MC. Gallstones and cholecystectomy in modernBritain. Postgrad Med J 2000; 76: 700-703.

[19]. Kang JY, Ellis C, Majeed A, et al. Gallstones - an increasing problem: a study of hospital admissions in England between 1989/1990 and 1999/2000. Aliment PharmacolTher2003; 17: 561-569.

[20]. Cox GR, Browne BJ. Acute cholecystitis in the emergency department. J Emerg Med 1989; 7: 501-511.

[21]. Tandy TK 3rd, Hoffenberg S. Emergency department ultrasound services by emergency physicians: Model for gaining hospital approval. Ann Emerg Med 1997; 29: 367-374.

[22]. Laing FC. Diagnostic evaluation of patients with suspected acute cholecystitis. RadiolClin North Am 1983; $21: 477-493$.

[23]. Rosen CL, Brown DF, Chang Y, et al. Ultrasonography by emergency physicians in patients with suspected cholecystitis. Am J Emerg Med 2001; 19: 32-36.

[24]. Ralls PW, Colletti PM, Halls JH, Siemsen JK. Prospective evaluation of 99mTc-IDA cholescintigraphy and gray-scaleultrasound in the diagnosis of acute cholecystitis. Radiology 1982; 144: 369-371.

[25]. Brachman MB, Tanasescu DE, Ramanna L, Waxman AD. Acute gangrenous cholecystitis radionuclide diagnosis. Radiology 1984; 151: 209-211.

[26]. Matolo NM, Stadalnik RC, McGahan JP. Comparison of ultrasonography, computerized tomography, and radionuclide imaging in the diagnosis of acute and chronic cholecystitis. Am J Surg 1982; 144: 676-681.

[27]. Summers SM, Scruggs W, Menchine MD, et al. A prospective evaluation of emergency department bedside ultrasonography for the detection of acute cholecystitis. Ann Emerg Med 2010; 56: 114-122.

[28]. Shaffer EA. Epidemiology and risk factors for gallstone disease: has the paradigm changed in the 21st century? CurrGastroenterol Rep 2005; 7: 132-140.

[29]. Schirmer BD, Winters KL, Edlich RF. Cholelithiasis and cholecystitis. J Long Term Eff Med Implants 2005; 15(3): 329-338.

[30]. Bingener J, Schwesinger WH, Chopra S, Richards ML, Sirinek KR. Does the correlation of acute cholecystitis on ultrasound and at surgery reflect a mirror image? Am J Surg 2004; 188: 703-707.

[31]. Rosen CL, Brown DF, Chang Y, et al. Ultrasonography by emergency physicians in patients with suspected cholecystitis. Am J Emerg Med 2001; 19: 32-36.

[32]. Chen RC, Liu H, Tu HY, Chen WT, Wang CS, Chiang LC,Cheni PH. The value of ultrasound measurement of gallbladder wall thickness in predicting laparoscopic operability prior to cholecystectomy. ClinRadiol 1995; 50: 570-572.

[33]. Habib FA, Kolachalan RB, Khilnani R, Preventza O, MittalVK. Role of laparoscopic cholecystectomy in the management of gangrenous cholecystitis. Am J Surg 2001; 181:71-75.

[34]. Miller AH, Pepe PE, Brockman CR, Delaney KA. ED ultrasound in hepatobiliary disease. Journal of EmergencyMedicine 2006; 30(1): 69-74. 